Case Report

\title{
A Late Presentation of a Fatal Disease: Juvenile Hemochromatosis
}

\author{
Cynthia Cherfane, ${ }^{1}$ Pauline Lee, ${ }^{2}$ Leana Guerin, ${ }^{3}$ and Kyle Brown ${ }^{1,4,5,6}$ \\ ${ }^{1}$ Department of Internal Medicine, Roy J. and Lucille A. Carver College of Medicine, University of Iowa, Iowa City, \\ IA 52242, USA \\ ${ }^{2}$ Department of Molecular and Experimental Medicine, The Scripps Research Institute, La Jolla, CA 92037, USA \\ ${ }^{3}$ Department of Pathology, Roy J. and Lucille A. Carver College of Medicine, University of Iowa, Iowa City, \\ IA 52242, USA \\ ${ }^{4}$ Iowa City Veterans Administration Medical Center, Iowa City, IA 52246, USA \\ ${ }^{5}$ Free Radical and Radiation Biology Program, Roy J. and Lucille A. Carver College of Medicine, University of Iowa, \\ Iowa city, IA 52242, USA \\ ${ }^{6}$ Division of Gastroenterology and Hepatology, University of Iowa, 200 Hawkins Drive, 4553 JCP, Iowa City, \\ IA 52242, USA
}

Correspondence should be addressed to Kyle Brown; kyle-brown@uiowa.edu

Received 14 March 2013; Accepted 13 August 2013

Academic Editor: Warren Schmidt

Copyright (C) 2013 Cynthia Cherfane et al. This is an open access article distributed under the Creative Commons Attribution License, which permits unrestricted use, distribution, and reproduction in any medium, provided the original work is properly cited.

Juvenile hemochromatosis is a rare and severe form of hereditary hemochromatosis. We report the case of a 39-year-old female who presented with heart failure and cirrhosis from previously unrecognized juvenile hemochromatosis. This is the latest presentation described in the literature. An important clue to the diagnosis was a history of amenorrhea since the age of 20 that had never been investigated. The patient died of intractable heart failure two months after the initial presentation. Juvenile hemochromatosis should be suspected in a young patient with endocrine or cardiac manifestations. Early diagnosis is crucial since phlebotomy can improve the prognosis and delay or prevent progression to heart failure and cirrhosis.

\section{Introduction}

In 1932, Bezançon et al. described a case of a 20 -year-old female with pigmentary cirrhosis, enlarged liver, infantilism, and multiple endocrine insufficiencies, who died of cardiac failure [1]. That was the first description of juvenile hemochromatosis (JH). In 1978, the disease was recognized as a distinct clinical entity with the description of a 26-year-old woman with heart failure, insulin-dependent diabetes, amenorrhea and hepatomegaly and a review of 52 previously reported cases of symptomatic idiopathic hemochromatosis [2, 3]. Since that time, there have been important discoveries that have clarified the molecular and genetic basis of this disorder, but limited progress has been achieved in improving its treatment, and JH is still often a fatal disease. We report the case of a woman who presented at the age of 39 with severe $\mathrm{JH}$.

\section{Case Presentation}

A 39-year-old Caucasian woman presented with palpitations and a two-week history of progressive fatigue, shortness of breath, and abdominal pain with distension. Her past medical history was significant for hypothyroidism on thyroid replacement therapy and amenorrhea since the age of 20 that had not been evaluated. Family history was pertinent for a first cousin who had died suddenly of "cardiac arrest" at 20 years old. Her mother and father were both in good health. There was no family history of iron overload or liver disease. The patient was an unmarried teacher. She had never smoked, rarely drank alcohol, and had no history of illicit drug use. Her physical exam showed mild jaundice and an irregular cardiac rhythm. The abdomen was diffusely tender with hepatomegaly, no splenomegaly or evident ascites. An electrocardiogram showed atrial fibrillation with rapid ventricular 
response, and an echocardiogram showed globally decreased left ventricular systolic function with an estimated ejection fraction of $26 \%$.

The patient was admitted to the cardiovascular intensive care unit where management of heart failure was initiated, her heart rate was controlled, and she was started on anticoagulation. Hematologic findings included a hemoglobin concentration of $13 \mathrm{~g} / \mathrm{dL}$, platelet count of $100 \mathrm{~K} / \mathrm{mm}^{3}$, and leucocyte count of $9.7 \mathrm{~K} / \mathrm{mm}^{3}$. Blood chemistries revealed the following results: total bilirubin $2.6 \mathrm{mg} / \mathrm{dL}$, direct bilirubin $1.1 \mathrm{mg} / \mathrm{dL}$, aspartate aminotransferase $1476 \mathrm{U} / \mathrm{L}$, alanine aminotransferase $702 \mathrm{U} / \mathrm{L}$, alkaline phosphatase $139 \mathrm{U} / \mathrm{L}$, gamma-glutamyl transpeptidase 52 , albumin $4.1 \mathrm{~g} / \mathrm{dL}$, and lactate dehydrogenase $968 \mathrm{U} / \mathrm{L}$. Review of the peripheral blood smear showed no evidence of hemolysis. Coagulation studies showed a prothrombin time of $20 \mathrm{sec}$ and an international normalized ratio (INR) of 2.1. Other relevant tests included thyroid-stimulating hormone $40 \mathrm{uIU} / \mathrm{mL}$ (normal $0.27-4.2$ ), free thyroxine $1.05 \mathrm{ng} / \mathrm{dL}$ (normal $0.93-$ 1.7 ), thyroid peroxidase autoantibody (anti-TPO) $1586 \mathrm{IU} / \mathrm{mL}$ (normal $<2$ ), follicle-stimulating hormone $0.3 \mathrm{mIU} / \mathrm{mL}$ (nor$\mathrm{mal} 3.5-12.5 \mathrm{mIU} / \mathrm{mL}$ ), and luteinizing hormone $0.1 \mathrm{mIU} / \mathrm{mL}$ (normal 2.4-12.6 mIU/mL). Abdominal ultrasound showed an enlarged liver with diffusely increased echogenicity, minimal ascites and normal-sized spleen. Doppler findings were consistent with congestive heart failure.

Testing for viral hepatitis and autoimmune serologies was negative. Alpha 1-antitrypsin and ceruloplasmin levels were normal. However, iron studies were markedly abnormal with a transferrin saturation of $100 \%$ and ferritin of $116,070 \mathrm{ng} / \mathrm{mL}$ (normal 22-322 ng/mL). Transjugular liver biopsy showed cirrhosis with $4+$ iron deposition in hepatocytes and in biliary epithelium, as well as focal centrilobular necrosis, likely due to congestion (Figure 1). HFE genotyping by the amplification refractory mutation system was negative for both $\mathrm{C} 282 \mathrm{Y}$ and H63D mutations. JH was suspected and further testing was performed on a research basis. Amplification of the HFE2 gene by polymerase chain reaction with genotyping by direct sequencing disclosed that the patient was homozygous for the HFE2 Gly320Val mutation (Figure 2).

Once her heart rate and congestive heart failure were controlled, she began weekly phlebotomies. Erythropoietin was administered because of concomitant anemia, but she did not undergo chelation. One month after her presentation, except for persistent fatigue, her symptoms had resolved. The ferritin level had decreased to $7400 \mathrm{ng} / \mathrm{mL}$. Unfortunately, two months later, after 8 phlebotomies, she was hospitalized for severe shortness of breath and hypotension. An echocardiogram showed worsening left ventricular function with ejection fraction of $10 \%$. She was intubated and treated with vasopressors and an intra-aortic balloon pump to maintain her blood pressure. Antiarrhythmic medications were given for recurrent nonsustained ventricular tachycardia. Despite the aggressive medical management, she developed multiorgan failure and died five days after admission. The family declined an autopsy. As part of family screening, her mother had iron studies done, which were normal. Her father and half-brother declined screening with iron studies.

\section{Discussion}

$\mathrm{JH}$ is an autosomal recessive form of hereditary hemochromatosis $(\mathrm{HH})$ characterized by severe iron overload presenting in early adulthood. In contrast to the more common form of $\mathrm{HH}$ associated with $\mathrm{HFE}$ mutations, in which iron overload-related disease predominates in males, men and women are equally affected in $\mathrm{JH}$. This may be explained in part by amenorrhea resulting from central hypogonadism in these young women [2]. In a review of 37 cases from Italy, the average age of presentation of $\mathrm{JH}$ was 23.6 years $[3,4]$. Our patient was 39, which is the oldest age of presentation of $\mathrm{JH}$ among the cases described in the literature. However, her long history of amenorrhea indicates that central hypogonadism predated the other manifestations of $\mathrm{JH}$. Reported incidences of hypogonadism and cardiomyopathy at presentation of $\mathrm{JH}$ are $94.6 \%$ and $43.2 \%$, respectively, and are the earliest and most frequent manifestations of $\mathrm{JH}$ [3]. It is hypothesized that this is secondary to a high susceptibility of the heart and the pituitary to iron at a younger age. The presence of cirrhosis at initial presentation is less common in $\mathrm{JH}$ (27\%); its presence in our patient may relate to her older age and longer duration of disease [2-4]. Given the increased level of TSH and anti-TPO, her hypothyroidism was most likely secondary to Hashimoto's disease rather than pituitary infiltration. Hashimoto's thyroiditis has been reported in two other $\mathrm{JH}$ cases [5]. The level of ferritin at presentation in our case was much higher than the mean level reported in the literature $(3217 \mathrm{ng} / \mathrm{mL})$ and likely reflected liver injury from congestive heart failure superimposed on iron overload [3].

Patients presenting with $\mathrm{HH}$ have mutations in the HFE gene in $85-90 \%$ of cases. The remaining patients have mutations in other genes [6-9]. Many of these have JH, which is also known as hemochromatosis type 2. This is a rare form of $\mathrm{HH}$ described worldwide, although its exact prevalence remains unknown [3]. JH type $2 \mathrm{~A}$ is associated with mutations in the HFE2 gene on chromosome 1q (previously known as HJV) [10-12] and accounts for $90 \%$ of cases of $\mathrm{JH}$. The HFE2 Gly320Val mutation seen in our patient is one of 47 mutations described in the HFE2 gene and is the most frequently reported mutation $[13,14]$. Compared to the low penetrance of the HFE mutations, all patients who have a homozygous mutation of the HFE2 gene will manifest the disease clinically, although clinical expression may be variable $[3,15]$.

The HFE2 gene encodes the hemojuvelin protein, which upregulates the expression of hepcidin, a hormone produced by the liver that plays a central role in the regulation of iron homeostasis. The target of hepcidin's action is ferroportin, an iron exporter expressed on the cell membranes of enterocytes and macrophages. Binding of hepcidin to ferroportin causes internalization and degradation of the latter protein, thereby blocking egress of iron from the cell [16]. Hepcidin expression is modulated by multiple physiologic stimuli acting through a variety of signaling pathways. Under normal circumstances, hepcidin increases in response to iron, a feedback mechanism that prevents iron overload. Upregulation of hepcidin expression by iron is mediated by a pathway involving bone morphogenetic protein 6 (BMP6). 


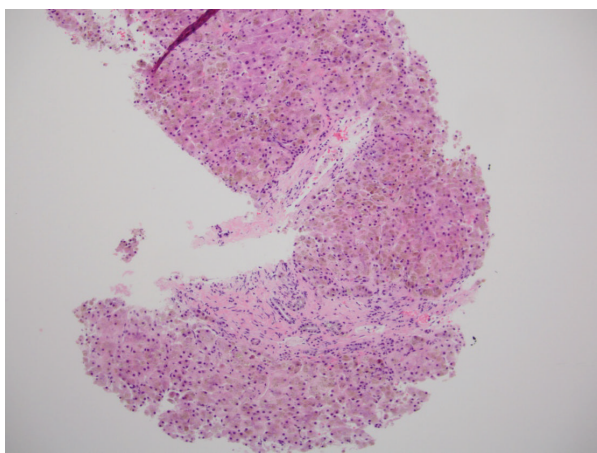

(a)

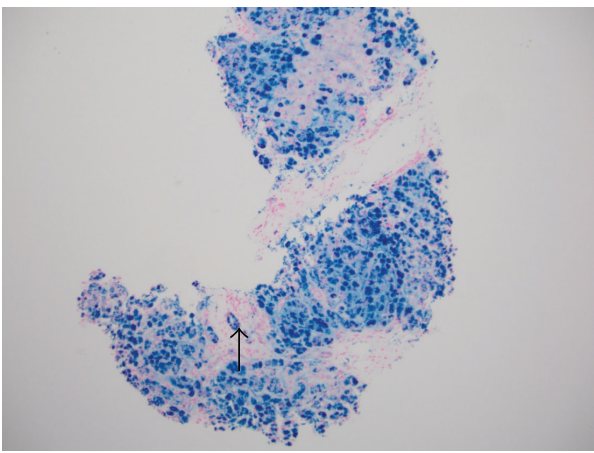

(c)

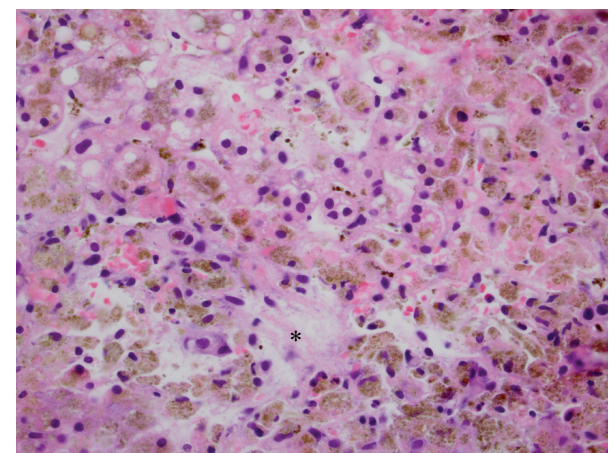

(b)

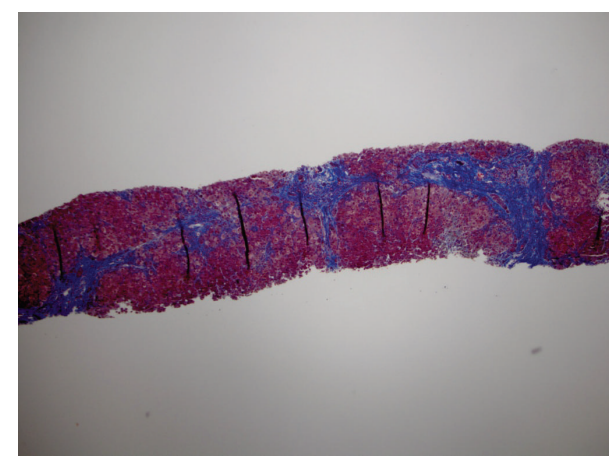

(d)

FiguRE 1: Liver biopsy from a young woman with juvenile hemochromatosis due to mutations in HFE2. (a) Iron appears as a brownish pigment in hepatocytes in this section stained with hematoxylin and eosin (10x magnification). (b) At higher power (40x magnification), the granular brown iron pigment is readily appreciated within hepatocytes. A small area of necrosis is indicated by the asterisk. (c) Perl's Prussian Blue stain confirms 4+ iron in hepatocytes as well as heavy iron deposition in the epithelium of a bile duct (arrow; 10x magnification). (d) Trichrome stain highlights the nodular contour of the hepatic parenchyma outlined by thick bands of connective tissue (4x magnification).

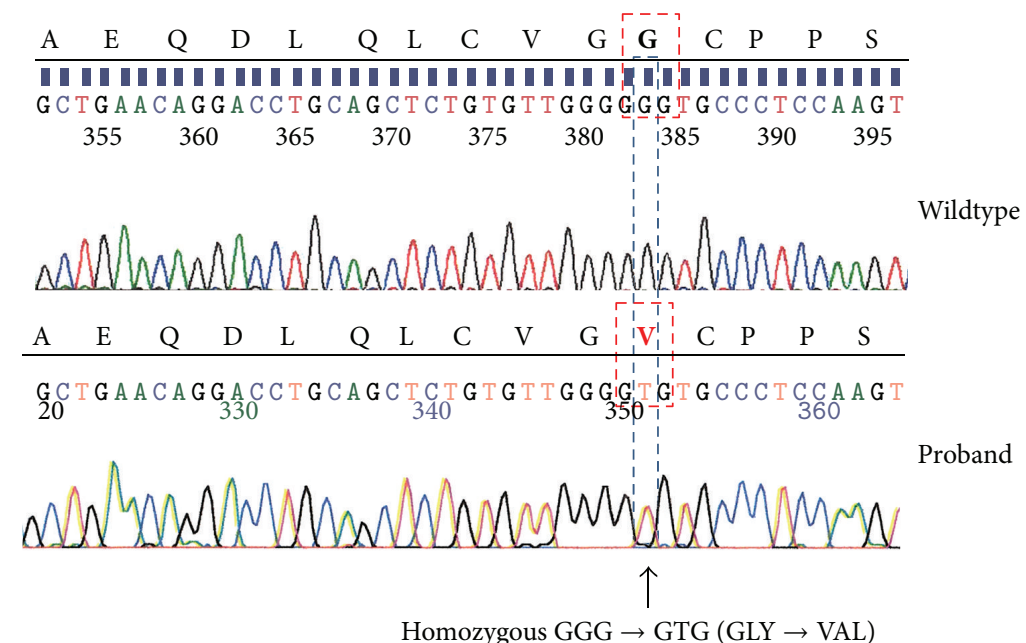

FIGURE 2: Sequencing demonstrating the hemojuvelin Gly320Val homozygous mutation.

Hemojuvelin is a BMP6 coreceptor on hepatocytes whose presence is required for induction of hepcidin expression by BMP6 [17]. The Gly320Val mutation causes a defect in the proteolytic processing of hemojuvelin that prevents targeting the protein to the plasma membrane and thus abrogates BMP6 signaling [18]. As a consequence, hepcidin expression no longer responds appropriately to iron status and iron overload ensues. A similar phenotype results from mutations in the gene encoding hepcidin itself, which accounts for the remaining $10 \%$ of cases of $\mathrm{JH}$ (type $2 \mathrm{~B}$ ) [19]. In addition, defective hepcidin responses and/or hepcidin resistance are common to the other forms of hereditary hemochromatosis as well as secondary iron overload [14].

$\mathrm{JH}$ is a life-threatening disease; however morbidity and mortality can be prevented or attenuated if diagnosed and treated early. Iron studies with ferritin and transferrin 
saturation should be done when the diagnosis is suspected. In those with increased iron parameters, HFE genotyping should be obtained.

Liver biopsy or magnetic resonance imaging should be considered to confirm iron overload in patients with elevated iron studies but without compatible HFE mutations [20]. The HFE2 Gly320V is the molecular test of choice in a young adult suspected to have JH [21-23]; however, genetic analysis for non-HFE forms of $\mathrm{HH}$ is not routinely available, leading to a clinical diagnosis in most cases. Phlebotomy is still considered the treatment of choice for JH. If initiated early, it can slow the progression of the disease and improve the prognosis [24-26]. In our patient, an early investigation of her amenorrhea could have yielded the diagnosis, allowing the initiation of phlebotomy and, potentially, a better outcome. Relative contraindications to phlebotomy include anemia, acute heart failure, and hemodynamic instability [26, 27]. After our patient was stabilized hemodynamically, she underwent weekly phlebotomies with improvement in her symptoms and decrease in her ferritin levels. She was not started on iron chelation therapy, but in retrospect, this should have been considered. There are limited but encouraging data on the use of iron chelation therapy in $\mathrm{JH}$ patients who present with decompensated heart failure, with improvement in cardiac function, blood counts, liver function, and ferritin levels after weeks to months of therapy. Single regimens with IV deferoxamine and combined regimens with deferiprone and deferoxamine have been used [27-30]. Erythropoietin has been suggested in anemic patients as a means of maintaining regular phlebotomies and increasing iron mobilization [31]. Heart transplant and placement of a pacemaker are two other potential treatments when heart failure and arrhythmias are present. Our patient may also have benefited from hormone replacement therapy for hypogonadotropic hypogonadism and prevention of osteoporosis, which is a frequent complication of JH [32].

In conclusion, our case illustrates the poor prognosis of $\mathrm{JH}$, in which delayed diagnosis and treatment resulted in severe cardiomyopathy and death in the fourth decade from heart failure and/or arrhythmia $[9,27]$. In retrospect, an aggressive regimen of chelation may have yielded a better outcome. Early suspicion in young patients with endocrine and/or cardiac disease and diagnosis with iron studies and genotype is crucial since early treatment with phlebotomy can change the natural history of the disease. With the better understanding of the disease at the molecular and biological levels, new therapies could be promising such as new chelating agents, exogenous transferrin, exogenous hepcidin, hepcidin analogues, and hepcidin signaling agonists [33]. Unfortunately, clinical trials to study the role of these new therapies and iron chelation therapy in $\mathrm{JH}$ are limited by the rarity of the disease.

\section{Acknowledgments}

Pauline Lee has received a Grant from the National Institutes of Health DK53505-12, and The Beutler Foundation. For the remaining authors, none were declared.

\section{References}

[1] F. Bezançon, L. de Gennes, J. Delarue, and V. Oumensky, "Cirrhose pigmentaire avec infantilisme, insuffisance cardiaque et aplasies endocriniennes multiples," Bulletins et Mémoires de la Société Médicale des Hôpitaux de Paris, vol. 48, pp. 967-974, 1932.

[2] J. M. Lamon, S. P. Marynick, R. Rosenblatt, and S. Donnelly, "Idiopathic hemochromatosis in a young female. A case study and review of the syndrome in young people," Gastroenterology, vol. 76, no. 1, pp. 178-183, 1979.

[3] C. Camaschella, A. Roetto, and M. de Gobbi, "Juvenile hemochromatosis," Seminars in Hematology, vol. 39, no. 4, pp. 242248, 2002.

[4] M. de Gobbi, A. Roetto, A. Piperno et al., "Natural history of juvenile haemochromatosis," British Journal of Haematology, vol. 117, no. 4, pp. 973-979, 2002.

[5] J. C. Barton, S. V. Rao, N. M. Pereira et al., "Juvenile hemochromatosis in the southeastern United States: a report of seven cases in two kinships," Blood Cells, Molecules and Diseases, vol. 29, no. 1, pp. 104-115, 2002.

[6] F.-Y. Dupradeau, S. Pissard, M.-P. Coulhon et al., "An unusual case of hemochromatosis due to a new compound heterozygosity in HFE (p.[Gly43Asp;His63Asp]+[Cys282Tyr]): structural implications with respect to binding with transferrin receptor 1," Human Mutation, vol. 29, no. 1, article 206, 2008.

[7] A. I. Mendes, A. Ferro, R. Martins et al., "Non-classical hereditary hemochromatosis in Portugal: novel mutations identified in iron metabolism-related genes," Annals of Hematology, vol. 88, no. 3, pp. 229-234, 2009.

[8] A. Pietrangelo, "Molecular insights into the pathogenesis of hereditary haemochromatosis," Gut, vol. 55, no. 4, pp. 564-568, 2006.

[9] A. Pietrangelo, "Non-HFE Hemochromatosis," Hepatology, vol. 39, no. 1, pp. 21-29, 2004.

[10] A. Roetto, A. Totaro, M. Cazzola et al., "Juvenile hemochromatosis locus maps to chromosome 1q," American Journal of Human Genetics, vol. 64, no. 5, pp. 1388-1393, 1999.

[11] A. Roetto, F. Alberti, F. Daraio et al., "Exclusion of ZIRTL as candidate gene of juvenile hemochromatosis and refinement of the critical interval on 1q21," Blood Cells, Molecules, and Diseases, vol. 26, no. 3, pp. 205-210, 2000.

[12] G. Papanikolaou, M. Politou, A. Roetto et al., "Linkage to chromosome 1q in Greek families with juvenile hemochromatosis," Blood Cells, Molecules, and Diseases, vol. 27, no. 4, pp. 744-749, 2001.

[13] G. Papanikolaou, M. E. Samuels, E. H. Ludwig et al., "Mutations in HFE2 cause iron overload in chromosome 1q-linked juvenile hemochromatosis," Nature Genetics, vol. 36, no. 1, pp. 77-82, 2004.

[14] A. Pietrangelo, A. Caleffi, and E. Corradini, "Non-HFE hepatic iron overload," Seminars in Liver Disease, vol. 31, no. 3, pp. 302318, 2011.

[15] E. Beutler, V. J. Felitti, J. A. Koziol, N. J. Ho, and T. Gelbart, "Penetrance of $845 \mathrm{G} \rightarrow \mathrm{A}(\mathrm{C} 282 \mathrm{Y}) \mathrm{HFE}$ hereditary haemochromatosis mutation in the USA," The Lancet, vol. 359, no. 9302, pp. 211-218, 2002.

[16] E. Nemeth, M. S. Tuttle, J. Powelson et al., "Hepcidin regulates cellular iron efflux by binding to ferroportin and inducing its internalization," Science, vol. 306, no. 5704, pp. 2090-2093, 2004 . 
[17] A.-S. Zhang, J. Gao, D. D. Koeberl, and C. A. Enns, "The role of hepatocyte hemojuvelin in the regulation of bone morphogenic protein- 6 and hepcidin expression in vivo," Journal of Biological Chemistry, vol. 285, no. 22, pp. 16416-16423, 2010.

[18] L. Silvestri, A. Pagani, C. Fazi et al., "Defective targeting of hemojuvelin to plasma membrane is a common pathogenetic mechanism in juvenile hemochromatosis," Blood, vol. 109, no. 10, pp. 4503-4510, 2007.

[19] A. Roettol, G. Papanikolaou, M. Politou et al., "Mutant antimicrobial peptide hepcidin is associated with severe juvenile hemochromatosis," Nature Genetics, vol. 33, no. 1, pp. 21-22, 2003.

[20] B. R. Bacon, P. C. Adams, K. V. Kowdley, L. W. Powell, and A. S. Tavill, "Diagnosis and management of hemochromatosis: 2011 practice guideline by the American Association for the Study of Liver Diseases," Hepatology, vol. 54, no. 1, pp. 328-343, 2011.

[21] M. Cazzola, E. Ascari, and G. Barosi, "Juvenile idiopathic haemochromatosis: a life-threatening disorder presenting as hypogonadotropic hypogonadism," Human Genetics, vol. 65, no. 2, pp. 149-154, 1983.

[22] P. C. J. L. Santos, J. E. Krieger, and A. C. Pereira, "Molecular diagnostic and pathogenesis of hereditary hemochromatosis," International Journal of Molecular Sciences, vol. 13, no. 2, pp. 1497-1511, 2012.

[23] S. G. Gehrke, A. Pietrangelo, M. Kaščák et al., "HJV gene mutations in European patients with juvenile hemochromatosis," Clinical Genetics, vol. 67, no. 5, pp. 425-428, 2005.

[24] A. S. Tavill, "Diagnosis and management of hemochromatosis," Hepatology, vol. 33, no. 5, pp. 1321-1328, 2001.

[25] A. Pietrangelo, "Hereditary hemochromatosis-a new look at an old disease," The New England Journal of Medicine, vol. 350, no. 23, pp. 2383-2430, 2004.

[26] P. Bring, N. Partovi, J.-A. E. Ford, and E. M. Yoshida, "Iron overload disorders: treatment options for patients refractory to or intolerant of phlebotomy," Pharmacotherapy, vol. 28, no. 3, pp. 331-342, 2008.

[27] G. Fabio, F. Minonzio, P. Delbini, A. Bianchi, and M. D. Cappellini, "Reversal of cardiac complications by deferiprone and deferoxamine combination therapy in a patient affected by a severe type of juvenile hemochromatosis (JH)," Blood, vol. 109, no. 1, pp. 362-364, 2007.

[28] T. Maeda, T. Nakamaki, B. Saito et al., "Hemojuvelin hemochromatosis receiving iron chelation therapy with deferasirox: improvement of liver disease activity, cardiac and hematological function," European Journal of Haematology, vol. 87, no. 5, pp. 467-469, 2011.

[29] P. C. J. L. Santos, R. D. Cançado, A. C. Pereira, C. S. Chiattone, J. E. Krieger, and E. M. Guerra-Shinohara, "HJV hemochromatosis, iron overload, and hypogonadism in a Brazilian man: treatment with phlebotomy and deferasirox," Acta Haematologica, vol. 124, no. 4, pp. 204-205, 2010.

[30] A. L. Kelly, D. A. Rhodes, J. M. Roland, P. Schofield, and T. M. Cox, "Hereditary juvenile haemochromatosis: a genetically heterogeneous life-threatening iron-storage disease," The Quarterly Journal Of Medicine, vol. 91, no. 9, pp. 607-618, 1998.

[31] M. de Gobbi, P. Pasquero, F. Brunello, P. Paccotti, U. Mazza, and C. Camaschella, "Juvenile hemochromatosis associated with $\beta$ thalassemia treated by phlebotomy and recombinant human erythropoietin," Haematologica, vol. 85, no. 8, pp. 865-867, 2000.

[32] N. G. Angelopoulos, A. K. Goula, G. Papanikolaou, and G. Tolis, "Osteoporosis in HFE2 juvenile hemochromatosis. A case report and review of the literature," Osteoporosis International, vol. 17, no. 1, pp. 150-155, 2006.

[33] R. E. Fleming and P. Ponka, "Mechanisms of disease: iron overload in human disease," The New England Journal of Medicine, vol. 366, no. 4, pp. 348-359, 2012. 


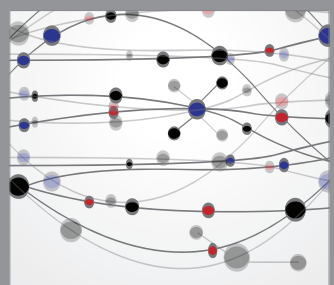

The Scientific World Journal
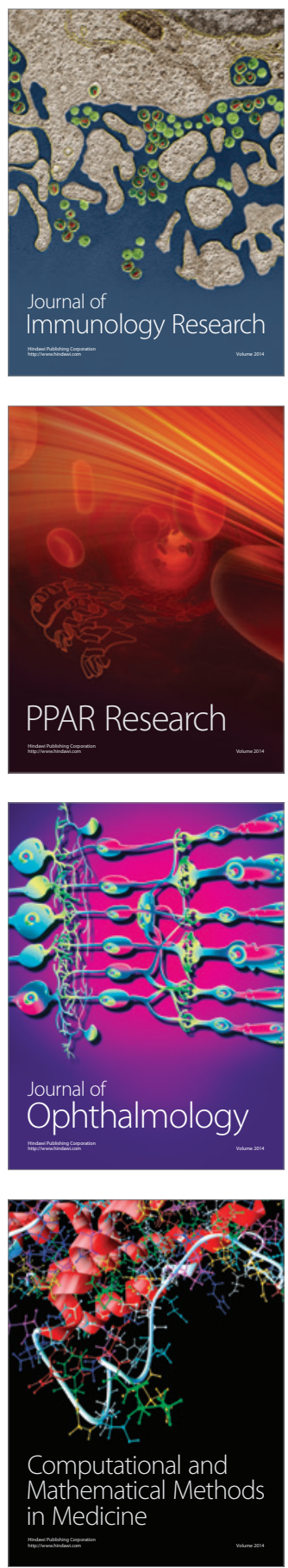

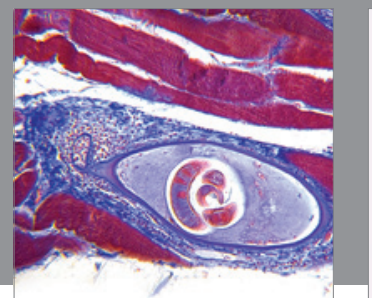

Gastroenterology

Research and Practice
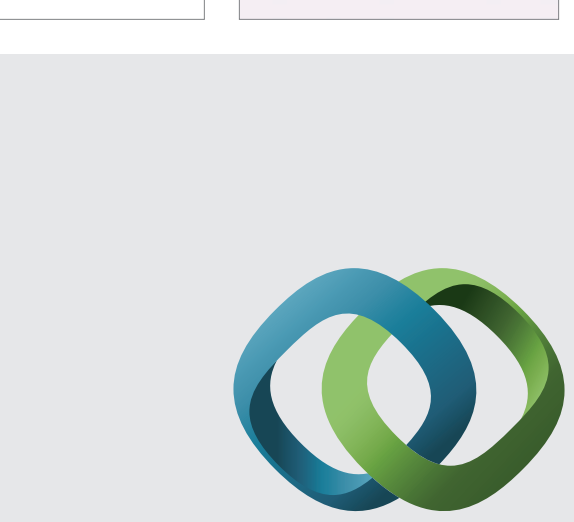

\section{Hindawi}

Submit your manuscripts at

http://www.hindawi.com
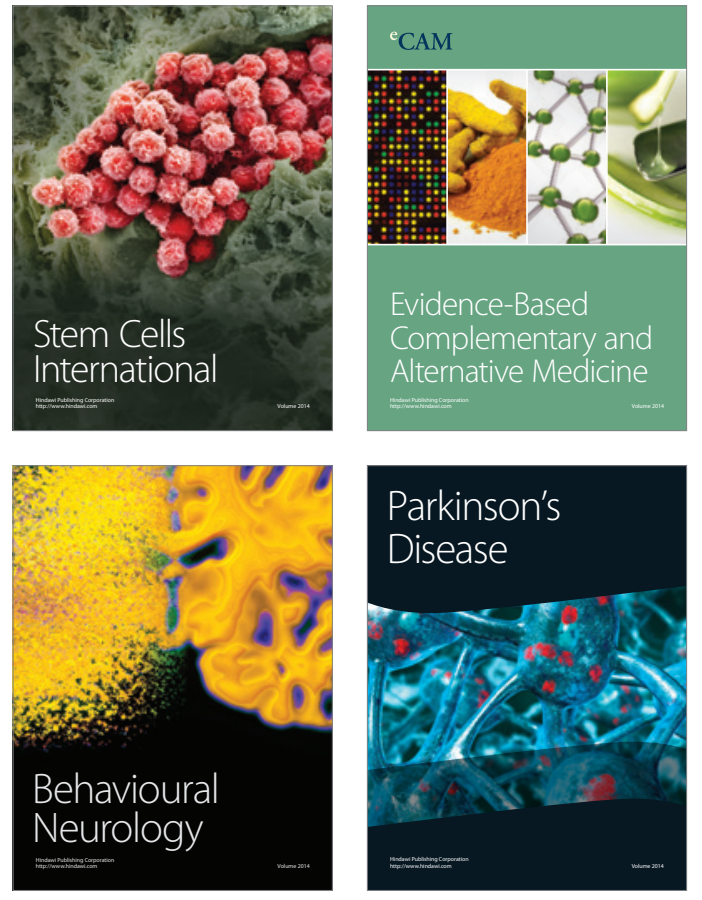
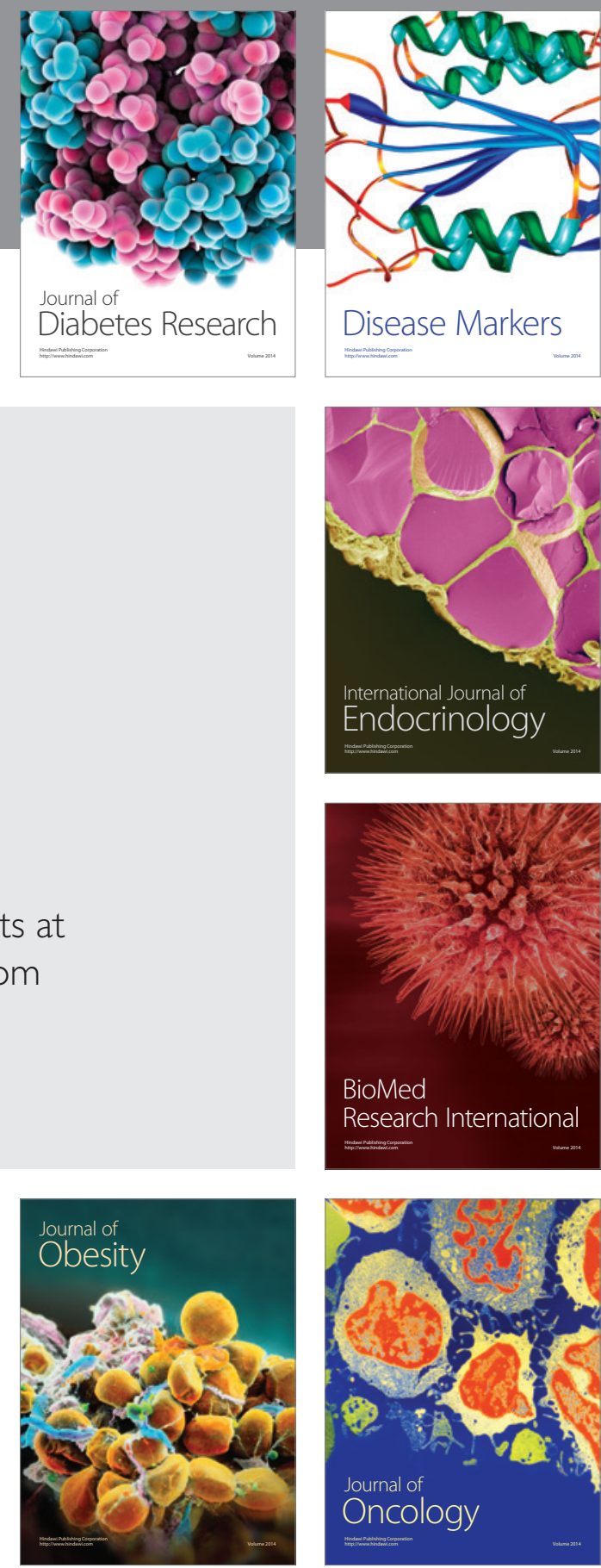

Disease Markers
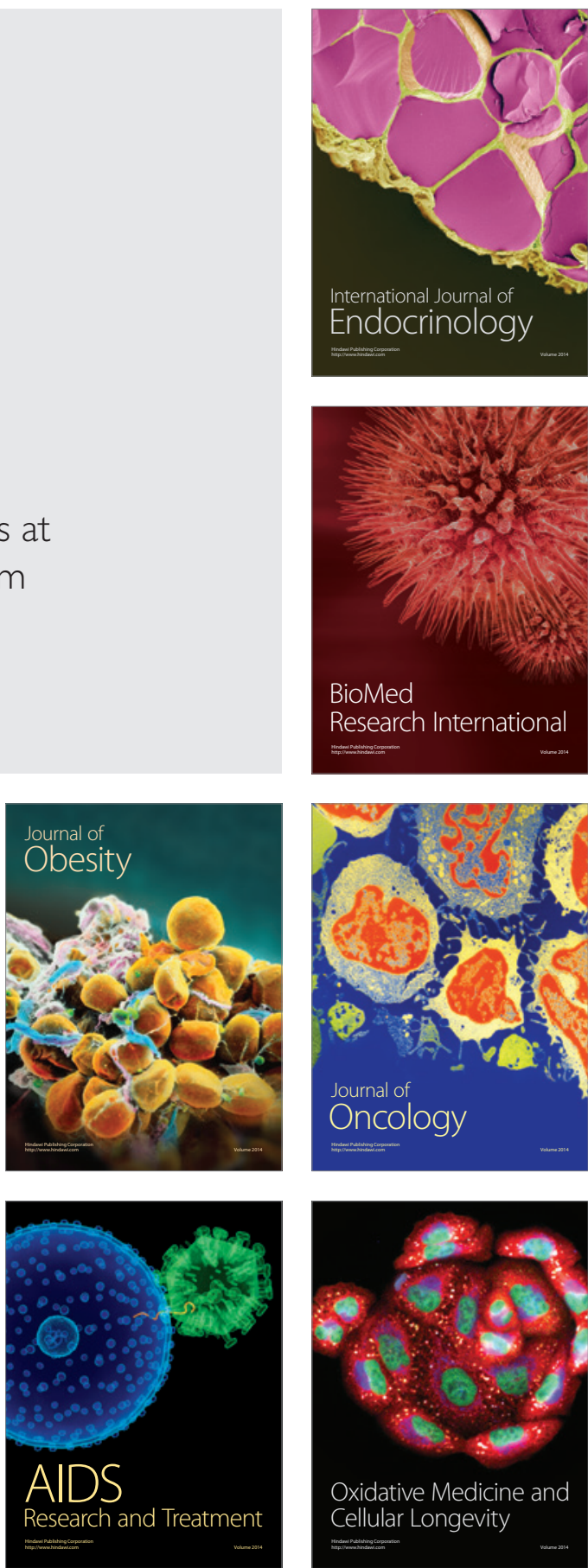